\title{
ARTICLE
}

\section{Application of MARSSIM for the Recycling of Radioactive Waste}

\author{
Hana SEO*, Jooho WHANG \\ Department of Nuclear Engineering, Kyunghee University
}

\begin{abstract}
Except reactor internals, the bioshield has most highly activated in the nuclear plant. According to the Korea Hydraulic Nuclear Power, there are beta and gamma nuclides like ${ }^{133} \mathrm{Ba},{ }^{41} \mathrm{Ca},{ }^{60} \mathrm{Co},{ }^{134} \mathrm{Cs},{ }^{152} \mathrm{Eu},{ }^{154} \mathrm{Eu},{ }^{155} \mathrm{Eu}$ in the Korea Nuclear Power Plant's bioshield. The number of samples varies from the guideline. And it was estimated using Multi-Agency Radiation and Site Investigation Manual. According to MARSSIM, the number of sample is statistically determined for reliability of data. When contaminants are not present in background, the Sign test is used for determining the number of samples. Sign test has 3 variances, significance level, power and guideline. Significance level and power are independent variables to class, the contamination level. The guideline was evaluated for site release and the recycle, respectively. Free release level $0.4 \mathrm{~Bq} / \mathrm{g}$ adopted for guideline was used for beta-gamma emitters in KRR decommissioning, for site release. And the guideline is derived using RESRAD-offsite from recycling regulation for the recycling of the radioactive waste. 281 samples for site release and 34 for the recycle are needed. The number of samples needed can be reduced by $12 \%$ for the recycle. Therefore, effects of considering the recycling instead of site releases are expected for reduction of sample needed, worker dose and the decommissioning cost.
\end{abstract}

\section{KEYWORDS: MARSSIM, survey sample, decommissioning, recycling, radioactive waste}

\section{Introduction}

About 6,200 tons of radioactive waste is generated when a Pressurized Water Reactor (PWR) is decommissioned. The cost for the disposal of the radioactive waste accounts for $13 \%$ of the total decommissioning cost. Currently researches are being done to find ways to recycle the radioactive waste to reduce its quantity. If a nuclear plant is decommissioned in consideration of recycling, the Final Status Survey (FSS) target will change, and consequently the number of survey data points and the exposure dose of survey workers are expected to change as well.

This study intends to discuss the impact that the decommissioning of bioshield concrete structures for the sake of recycling has on the number of measurement samples and the exposure dose of survey workers.

\section{Samples for Final Status Survey}

Methods used in Korea to determine the final status when decommissioning a nuclear plant have much to be desired. The greater the sample size, the more reliable measurements are. But it surely entails exposure of workers and higher costs. Accordingly, the US is applying the Multi-Agency Radiation Survey and Site Investigation Manual (MARSSIM) methodology to statistically determine a sample size that ensures the reliability of data. MARSSIM uses the characterization survey and scoping survey to predict radioactivity in the radioactive waste. This value is compared with the release or allowable surface contamination level to determine the sample size ${ }^{1}$.

At this time, depending on whether or not the nuclide in the waste targeted for measurement is in the reference area, the method of determining the number of data points varies. The Sign Test is used for the following nuclides, which exist in the bioshield structure but do not exist in the reference area, to determine the number of data points.

The Sign Test is used to determine whether or not the mean of a population exceeds a certain value. In general, it is applied when the radioactivity of facilities and buildings inside the lot is measured. The number of data points is determined as follows:
${ }^{*}$ Corresponding Author, Tel. +82-10-3305-9059,

Fax.+82-31-202-5973, E-mail:jtta86@lycos.co.kr

$$
N=\frac{\left(Z_{1-\alpha}+Z_{1-\beta}\right)^{2}}{4(\operatorname{Sign} P-0.5)^{2}}
$$


Where,

$\mathrm{N}=$ number of data points

$Z_{1-\alpha}=$ Type I error $(\alpha)$ percentile

$Z_{1-\beta}=$ Type II error $(\beta)$ percentile

Sign $\mathrm{P}=$ the estimated probability that a random measurement from the survey unit will be less than the $\mathrm{DCGL}_{\mathrm{w}}$ when the survey unit median is actually at the LBGR

Here, $\alpha$ is the significance level, i.e. the probability of saying there is contamination when there is no contamination. $\beta$ refers to the probability of saying there is no contamination when there is contamination. The smaller the $\beta$ value is, the greater the power of the test. It is recommended that $\alpha$ and $\beta$ be determined depending on the contamination level of the measurement target. As the radioactivity of the bioshield is lower than that of reactor internals, it is assumed to be class 2. Accordingly, $\alpha$ and $\beta$ will be 0.025 and 0.05 respectively, whereas $Z_{1-\alpha}$ will be 1.96 , and $Z_{1-\beta} 1.645$. The Sign $p$ is used to calculate the minimum number of data points necessary for the survey to meet the DQOs. The value of the relative shift calculated in the previous section is used to obtain the corresponding value of Sign $\mathrm{p}$.

Relative shift can be determined as follows:

$$
\frac{\Delta}{\sigma}=\frac{D C G L-L B G R}{\sigma}
$$

Where,

DCGL $=$ Derived Concentration Guideline Level

LBGR $=$ Lower Bound of the Gray Region

$\sigma \quad=$ an estimate of the standard deviation of the measured values in the survey unit

$\sigma$ was calculated through the characterization survey prior to the final status survey. If it is not measured in advance, it will be $30 \%$. LBGR is usually $1 / 2$ of DCGLgross, and it is recommended that the relative shift be greater than 1 and smaller than 3 .

In general, the purpose of FSS is site release. At this time, CGL is the specific activity of each nuclide calculated in a way fit for the acceptable level of dosage for site release. If recycling is taken into consideration, however, DCGL must comply with the guideline for satisfying the recycling standard. Therefore, this study intends to determine how much the change of DCGL affects the number of samples.

\section{Conditional Release}

When the concrete structure of the Korea Research Reactor, KRR-2, was decommissioned, $0.04 \mathrm{~Bq} / \mathrm{g}$ and 0.4 $\mathrm{Bq} / \mathrm{g}$ were applied to the conditional level for alpha nuclide, and for beta and gamma nuclide respectively. The nuclides expected to be detected from the bioshield of the Korea Standard Nuclear Power Plant (KSNP) are as follows ${ }^{2}$ :

$$
{ }^{133} \mathrm{Ba},{ }^{41} \mathrm{Ca},{ }^{60} \mathrm{Co},{ }^{134} \mathrm{Cs},{ }^{152} \mathrm{Eu},{ }^{154} \mathrm{Eu},{ }^{155} \mathrm{Eu} .
$$

As all of them are beta and gamma emitting nuclides, 0.4 $\mathrm{Bq} / \mathrm{g}$ of DCGL will be applied.

$$
\begin{gathered}
\text { DCGL }=0.4 \mathrm{~Bq} / \mathrm{g} \\
\text { SignP }=0.617911 \\
\mathrm{~N}=234
\end{gathered}
$$

At this time, $120 \%$ of the $\mathrm{N}$ value calculated to prevent the loss of samples or data will be actually measured.

$$
\mathrm{N}_{\text {gross }}=281
$$

To decide on the release of the radioactive concrete waste from the site, 281 samples must be measured before the reliability of the data is ensured.

\section{Recycling}

Korea applies its own disposal regulation instead of the regulation for recycling radioactive waste $^{3}$. The nuclides in the KSNP bioshield must meet its self-disposal regulation of $10 \mu \mathrm{Sv} / \mathrm{yr}$. Assuming that it will be used as a backfill material for the LLW disposal facility, DCGLs calculated with RESRAD-Offsite are shown in Table $\mathbf{1}^{4}$. If there is DCGL for each nuclide, the gross DCGL of all nuclides is determined as follows:

$$
D C G L_{\text {gross }}=\frac{1}{\frac{f_{1}}{D C G L_{1}}+\frac{f_{2}}{D C G L_{2}}+\cdots+\frac{f_{n}}{D C G L_{n}}}
$$


Where,

$$
\begin{aligned}
\text { DCGL }_{\text {gross }}= & \text { Derived Concentration Guideline Level of all } \\
& \text { nuclides } \\
\mathrm{f}_{\mathrm{n}} & \text { fraction of } \mathrm{n}^{\text {th }} \text { nuclide's concentration } \\
\text { DCGL }_{\mathrm{n}}= & \text { DCGL of } \mathrm{n}^{\text {th }} \text { nuclide }
\end{aligned}
$$

$\mathrm{f}_{\mathrm{n}}$, indicates the radioactivity of the $1 \mathrm{~m}$ inside wall of the recyclable KSNP bioshield satisfying the DCGLs in Table 1, was obtained.

Table 1 Comparison of bioshield concentration and DCGLs

\begin{tabular}{|c|c|c|c|c|}
\hline & $\begin{array}{c}\text { Bioshield } \\
1 \mathrm{~m} \\
\text { concentration }\end{array}$ & $\mathrm{f}_{\mathrm{n}}$ & DCGL & $\mathrm{f}_{\mathrm{n}} / \mathrm{DCGL}$ \\
\hline${ }^{133} \mathrm{Ba}$ & $7.09 \mathrm{E}+00$ & $9.71 \mathrm{E}-01$ & $9.95 \mathrm{E}+00$ & $9.76 \mathrm{E}-02$ \\
\hline${ }^{41} \mathrm{Ca}$ & $4.08 \mathrm{E}-03$ & $5.59 \mathrm{E}-04$ & $3.02 \mathrm{E}+01$ & $1.85 \mathrm{E}-05$ \\
\hline${ }^{60} \mathrm{Co}$ & $2.93 \mathrm{E}-05$ & $4.02 \mathrm{E}-06$ & $7.08 \mathrm{E}+00$ & $5.67 \mathrm{E}-07$ \\
\hline${ }^{134} \mathrm{Cs}$ & $3.00 \mathrm{E}-02$ & $4.10 \mathrm{E}-03$ & $1.71 \mathrm{E}+01$ & $2.39 \mathrm{E}-04$ \\
\hline${ }^{152} \mathrm{Eu}$ & $1.64 \mathrm{E}-01$ & $2.24 \mathrm{E}-02$ & $4.79 \mathrm{E}+00$ & $4.68 \mathrm{E}-03$ \\
\hline${ }^{154} \mathrm{Eu}$ & $1.19 \mathrm{E}-02$ & $1.63 \mathrm{E}-03$ & $8.48 \mathrm{E}+00$ & $1.92 \mathrm{E}-04$ \\
\hline${ }^{155} \mathrm{Eu}$ & $2.70 \mathrm{E}-03$ & $3.69 \mathrm{E}-04$ & $1.28 \mathrm{E}+02$ & $2.88 \mathrm{E}-06$ \\
\hline Total & & & & $1.03 \mathrm{E}-01$ \\
\hline
\end{tabular}

DCGL $_{\text {gross, }}$, calculated on this basis, is shown below.

$$
\begin{gathered}
\text { DCGL }_{\text {gross }}=9.74 \mathrm{~Bq} / \mathrm{g} \\
\text { SignP }=0.99865 \\
\mathrm{~N}=28 \\
\mathrm{~N}_{\text {gross }}=34
\end{gathered}
$$

The reliability of the data for recycling the radioactive concrete waste can be ensured if there are 34 samples. It means that only about $12 \%$ of the samples needed for taking the waste out of the site can ensure the reliability of the data.

\section{Occupational Dose}

MARSSIM recommends direct measurement in case the surface of the building is measured for the deregulation of the building. If the $\mathrm{NaI}$ (TI) measuring instrument, which has the best measurement efficiency, is used for measurement, the measurement time for each sample must be about 600 minutes ${ }^{5}$. The worker's exposure dose, calculated by means of the RESRAD-build code, is shown below.

\section{Conditional Release}

281 samples are needed for measurement for the sake of taking the waste outside of the site. It will take 168,600 minutes to measure them, and considering the working time (12 hours), the measurement will take approximately 0.64 years.

With the structures of the bioshield not completely decommissioned, this study evaluated the exposure dose of a worker measuring 281 samples over a period of about 1.3 years. The structure of the bioshield was divided into two, and the source term and shielding material were entered. Depending on the possibility of recycling, the source term was divided into the concrete $1 \mathrm{~m}$ from the inside wall, and the outside thereof. For the point $1 \mathrm{~m}$ away from the inside wall 4 source terms containing the radioactivity of the inside wall were deployed, and 4 source terms containing the radioactivity of the $1 \mathrm{~m}$ wall were deployed for the outside. Each source term was evaluated based on the assumption that it also served as a shielding wall. Source terms are shown in Table 2 below.

The evaluated TEDE is $1.98 \mathrm{E}-01 \mathrm{mSv}$, whereas the collective dose is 1.58E-01 Man.Sv.

\section{Recycling}

If measurements are taken for the purpose of recycling, 34 samples are needed. This measurement takes 17,000 minutes, which is equivalent to about 0.06 years.

The exposure dose of a worker, measuring 34 samples for about 0.12 years following the removal of the concrete structure from the inside wall to be classified as radioactive waste to the point $1 \mathrm{~m}$ away from the inside wall, was evaluated. Information about the worker was assumed as described in the previous paragraph. Afterwards, 4 source terms were deployed around the worker as shown in Table 2 describing the radioactivity of the $1 \mathrm{~m}$ wall.

The evaluated TEDE is $3.23 \mathrm{E}-07 \mathrm{mSv}$, while the collective dose is 2.58E-07 Man.Sv. Considering the fact that the Maine Yankee nuclear plant spent \$2,000 to reduce the worker's exposure dose by 1 Man.Sv, the dose is 
equivalent to approximately $\$ 310^{6}$.

Table 2 Source term to the survey worker for the site release or the recycling

\begin{tabular}{|c|c|c|c|}
\hline \multirow{2}{*}{ Nuclide } & \multicolumn{2}{|c|}{ Site release } & Recycling \\
\cline { 2 - 4 } & Inner-1 m & 1 m-outer & $1 \mathrm{~m}$-outer \\
\hline${ }^{133} \mathrm{Ba}$ & $2.17 \mathrm{E}+04$ & $7.09 \mathrm{E}+00$ & $7.09 \mathrm{E}+00$ \\
\hline${ }^{41} \mathrm{Ca}$ & $1.25 \mathrm{E}+01$ & $4.08 \mathrm{E}-03$ & $4.08 \mathrm{E}-03$ \\
\hline${ }^{60} \mathrm{Co}$ & $3.45 \mathrm{E}+02$ & $2.93 \mathrm{E}-05$ & $2.93 \mathrm{E}-05$ \\
\hline${ }^{134} \mathrm{Cs}$ & $2.55 \mathrm{E}+02$ & $3.00 \mathrm{E}-02$ & $3.00 \mathrm{E}-02$ \\
\hline${ }^{152} \mathrm{Eu}$ & $1.87 \mathrm{E}+06$ & $1.64 \mathrm{E}-01$ & $1.64 \mathrm{E}-01$ \\
\hline${ }^{154} \mathrm{Eu}$ & $1.41 \mathrm{E}+05$ & $1.19 \mathrm{E}-02$ & $1.19 \mathrm{E}-02$ \\
\hline${ }^{155} \mathrm{Eu}$ & $7.70 \mathrm{E}+03$ & $2.70 \mathrm{E}-03$ & $2.70 \mathrm{E}-03$ \\
\hline
\end{tabular}

\section{Conclusion}

If radioactive waste is recycled, its quantity will be reduced, thereby saving disposal and decommissioning costs. Also, as the number of data points required for the measurement performed for the sake of recycling is reduced, the exposure dose of the survey worker will also be lowered. If the bioshield is decommissioned in consideration of recycling, the number of measured data points will decrease

by $12 \%$ as compared to when it is decommissioned only for site release. The exposure dose of the survey worker declines, but the effect converted into costs is negligible as compared to the reduction in disposal costs.

\section{Acknowledgment}

This work is the outcome of a Manpower Development Program for Energy \& Resources supported by the Ministry of Knowledge and Economy (MKE).

\section{References}

1) NRC, Multi-Agency Radiation Survey and Site Investigation Manual, NUREG-1575, 2000.

2) Korea Hydro and Nuclear Power Co., Ltd., nuclear plant development of the post-treatment cost assessment system, 2009.

3) Ministry of Education, Science and Technology, notification of the regulation on the self-disposal of radioactive waste, MEST notification 2008-64, 2008.

4) European Commission (EC), Definition of clearance levels for the release of radioactively contaminated buildings and building rubble, EC-RP-114, 1999.

5) C. Y. Yi, J. S. Jun, H. S. Chai, J. J. Oh and J. Y. Yun, Measurement of ambient dose equivalent using a NaI scintillation detector, Journal of Radiation Protection Dosimetry 74(4), 1997.

6) Maine Yankee Atomic Power Company, Maine Yankee License Termination Plan, 2005. 